\title{
A knowledge-based integrated aircraft conceptual design framework
}

Raghu Chaitanya Munjulury, Ingo Staack, Patrick Berry and Petter Krus

\author{
Linköping University Post Print
}

Tweet

N.B.: When citing this work, cite the original article.

The original publication is available at www.springerlink.com:

Raghu Chaitanya Munjulury, Ingo Staack, Patrick Berry and Petter Krus, A knowledge-based integrated aircraft conceptual design framework, 2016, CEAS Aeronautical Journal, (7), 1, 95105.

http://dx.doi.org/10.1007/s13272-015-0174-z

Copyright: Springer Verlag (Germany)

http://www.springerlink.com/?MUD=MP

Postprint available at: Linköping University Electronic Press

http://urn.kb.se/resolve?urn=urn:nbn:se:liu:diva-126689 


\title{
A Knowledge-Based Integrated Aircraft Conceptual Design Framework
}

\author{
Raghu Chaitanya Munjulury, Ingo Staack, Patrick Berry, Petter Krus
}

Received: date / Accepted: date

\begin{abstract}
The conceptual design is the early stage of aircraft design process where results are needed fast, both analytically and visually so that the design can be analyzed and eventually improved in the initial phases. Although there is no necessity for a CAD model from the very beginning of the design process, it can be an added advantage to have the model to get the impression and appearance. For this purpose, knowledge-based aircraft conceptual design applications Tango (Matlab) and RAPID (CATIA) are being developed at Linköping University. Based on a parametric data definition in $X M L$, this approach allows for a full 3D CAD integration.

The one-database approach, also explored by many research organizations, enables the flexible and efficient integration of the different multidisciplinary processes during the whole conceptual design phase. This paper describes the knowledge-based design automated methodology of RAPID, data processing between RAPID and Tango and its application in the courses "Aircraft conceptual design" and "Aircraft project course" at Linköping University. A multifaceted user interface is developed to assist the whole design process.
\end{abstract}

Keywords Aircraft Conceptual Design · Knowledge Based · XML Database

Raghu Chaitanya Munjulury

Linköping University, SE-581 83, Linköping, Sweden

Tel.: +46-13-281155

E-mail: raghu.chaitanya@liu.se

Ingo Staack

Linköping University, SE-581 83, Linköping, Sweden

Patrick Berry

Saab Aeronautics, SE-581 88, Linköping, Sweden

Petter Krus

Linköping University, SE-581 83, Linköping, Sweden
This Paper is based on conference papers 182 and 183 presented at the Proc. CEAS European Air and Space Conference, Linköping, Sweden, 2013
Abbreviations
$A R$
$C A D$
Aspect Ratio
$C A D L a b$
Computer Aided Design
CATIA
Conceptual Aircraft Design Laboratory
Computer Aided Three-Dimensional
DOM Document Object Model
$E K L \quad$ Engineering Knowledge Language
$F A R \quad$ Federal Acquisition Regulation
$K B S \quad$ Knowledge Based System
$K B E \quad$ Knowledge Based Engineering
$K P \quad$ Knowledge Pattern
$P C \quad$ Power Copy
$R A P I D \quad$ Robust Aircraft Parametric Interactive Design
$S F C \quad$ Specific Fuel Consumption
TR Taper Ratio
$U D F \quad$ User Defined Feature
$V B \quad$ Visual Basic
$V B A \quad$ Visual Basic for Applications
$X M L \quad$ Extensible Markup Language
XLST Extensible Stylesheet Language

\section{List of Symbols}

$\begin{array}{ll}A_{R} & \text { Aspect ratio } \\ C_{S} & \text { Fuselage cross-section } \\ C_{S}^{i} & i^{t h} \text { cross-section } \\ C_{u} & \text { Upper curve } \\ C_{l} & \text { Lower curve }\end{array}$


$C_{c}$

$f_{i}(Z)$

$f_{u}$

$H_{f}$

$k$

$L_{f}$

$n_{p}$

$P_{i}$

$p_{1,2, \ldots 7}$

$S$

$S_{p}$

$w$

$w_{p}$

$w_{p}^{i}$

$W_{f}$

$\Gamma$

$\theta$

$\lambda$

$\Lambda$

$\alpha_{p_{2,3,5,6}}$
Combine curve

Piecewise polynomial functions

Fuselage function

Height of fuselage

Kink Position

Length of fuselage

Number of parameters

Points on a spline

Control points of cross-section

Reference wing area

Splines

Wing function

Wing partitions

$i^{\text {th }}$ wing partition

Width of fuselage

Dihedral

Incidence/Twist

Taper ratio

Sweep

Angle measured w.r.t horizontal or vertical

\section{Introduction}

Conceptual design tools have a constant need for refinement and improvement. One much-needed enhancement is the ability to communicate between analytical design tools and the 3D environment. Data communication between conceptual design programs has always been a major obstacle which now has one of a possible solution through this work, presently being done at Linköping University. A seamless connection appeals to the designer, but it has to work both ways. There are a handful of existing software tools in the industry, at universities and research centers. Some have connections to CAD software, but the connection is usually not seamless and rarely they work bi-directional [1].

Existing aircraft conceptual design tools are:

- Aircraft design software package ("Raymer's Design System") RDS-Student [2]

- Vehicle Sketch Pad (VSP) [3]

- Conceptual Design Tool (CDT) [4]

- J2 Universal Tool Kit [5]

- Aircraft Design Software (ADS) [6]

- Piano [7]

- Rapid Aerospace Geometry Engine (RAGE) [8]

- Computerized Environment for Aircraft Synthesis and Integrated Optimization Methods (CEASIOM) [9]

- Preliminary Aircraft Design Lab (PADLab) [10]

\section{CADLab: A data-centric Conceptual Aircraft} Design Framework

In order to allow for a seamless CAD integration, a data-centric conceptual aircraft design framework named CADLab (Conceptual Aircraft Design Laboratory) has been developed. The intentional naming ambiguity with the usual abbreviation of "CAD" for Computer Aided Design highlights one of the unique topics that characterize this framework besides the extended usage of $\mathrm{KBE}$ and system architecture design. A CAD tool is the natural means for geometry modelling and therewith the user can continue to work within the preferred CAD environment. Furthermore, the direct usage of CAD allows for a direct geometry propagation from the conceptual design to the preliminary design by adding new elements to the existing geometry.

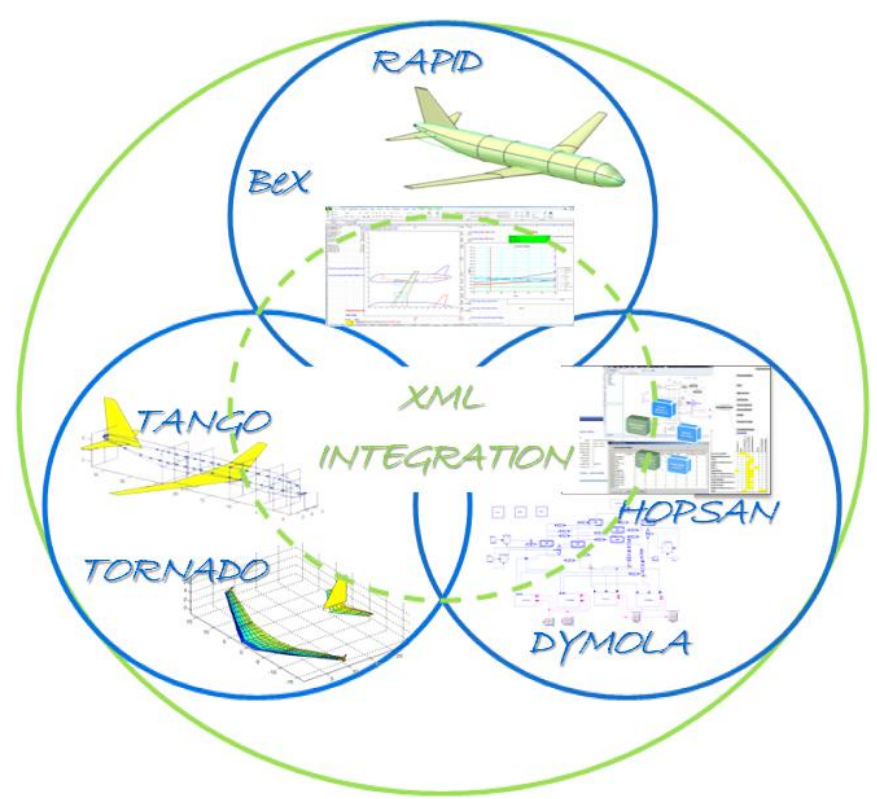

Fig. 1 CADLab Framework [11]

At a glance, the framework consists of three modules: A sizing/CAD module, an estimation, analysis and assessment module and a simulation \& system architecture module, shown in Fig. 1. All the modules communicate and interact with a central XML database. One of the development target of this framework was to enable parallel functionality. The highly KBE based CAD and aircraft sizing module serves for a fast setup of the initial design, usually based on a conceptual sizing. Main part of this module is RAPID (see Fig. 3), a geometry oriented design tool implemented in CATIA ${ }^{\circledR}$ [12].

After instantiating geometry and the related primary structure, the design analysis is conducted in the analysis module regarding aerodynamic, weight and struc- 
ture, trim and flight envelope as well as propulsion and system performance. This analysis functionality is mainly based on semi-empirical (statistical) data and the Vortex Lattice aerodynamic analysis, conducted in Tornado [13]. Within this module the requirement mission(s) are calculated based on the available data and the results are presented to the user. It can take consideration to additional data, usually the structural weight and the supersonic wave drag [14] from RAPID and system performance and weight properties of the simulation \& system architecture module.

The third module, simulation \& system architecture is used for more detailed investigations. This address problematics like system architecture design, system integration and the analysis of system interaction; these capabilities are used e.g., to investigate different control/actuator architectures or to investigate positive and negative system interferences. This is especially necessary for tightly coupled systems like the nowadays highly electrical driven on-board systems of civil passenger aircrafts. Stability and control design - inevitably included in the flight control system of unstable configurations - is also a topic addressed in this module, supporting the user with (faster than real time) simulations which allow the designer to investigate and understand the system characteristics and capabilities. These features had been enabled by the extended usage of KBE processes during the simulation model instantiation.

\subsection{Knowledge Based Engineering Design}

Knowledge Based Engineering (KBE) is a technology of reusing information initiated by Concentra Corporation [15] and is in existence for a couple of decades. More and more people have seen the need [16] and also developed an application in aircraft design based on KBE [17]. The main application of KBE (automation) are repetitive, rule-based or statistical data based processes which can be either a manual, semi-automatic or automatic processes [11] [18] [19]. Nowadays, most CAD software are embedded with this technology as packages like e.g., Knowledgeware in CATIA. In conceptual aircraft design, this applies to the initial concept generation comprising layout selection, sizing, geometry instantiation including basic aircraft structure and onboard systems design.

$\mathrm{KBE}$ automation within the CAD environment is implemented by Knowledge Pattern (KP) and Visual Basic for Application (VBA). A KP based instantiation consist of a User Defined Feature (UDF), catalog and script. The UDF captures the knowledge of the object

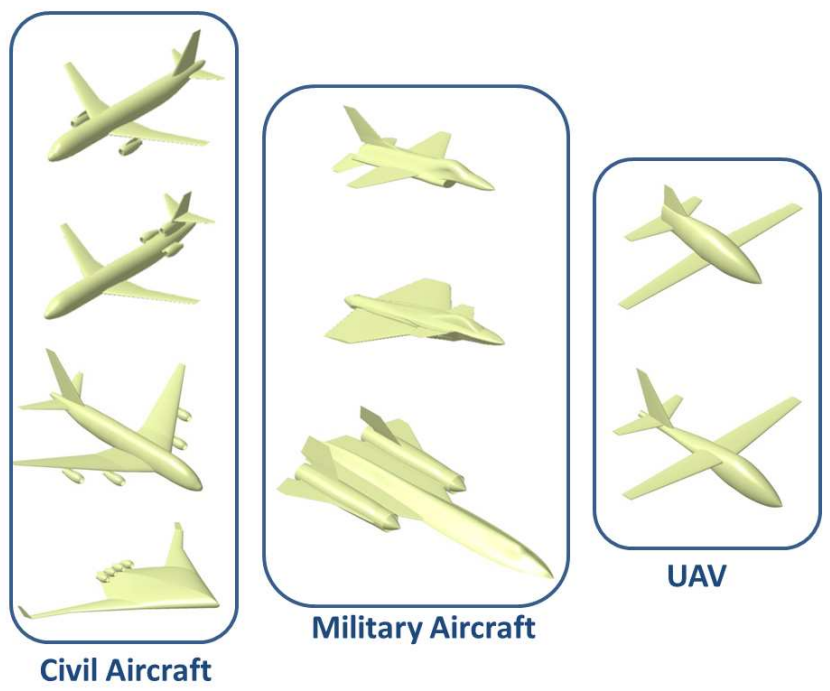

Fig. 2 Different aircraft configurations of geometry model in RAPID

to be instantiated during automation process. The catalog stores the location of the UDF and the KP script - written in Engineering Knowledge Language (EKL) helps to automate the process.

To instantiate using VBA, the knowledge is stored in a Power Copy (PC) and Visual Basic scripts are used. The significant differences and advantages of the two implementation methods mentioned above are explained in detail in [20]. A wide variety of aircraft configurations is modelled by this KBE design process is shown in Fig. 2. In the next Section, RAPID and its KBS geometry definitions are explained in detail.

\section{Robust Aircraft Parametric Interactive Design - RAPID}

RAPID (Fig. 3) is a geometry oriented design tool developed as a part of CADLab. A design from a blank sheet of paper is obtained by bottom-up design approach (see Fig. 5(b)) or an existing aircraft model is loaded from the XML data library (see Fig. 4) or the aircraft is updated directly from sizing (see Fig. 5(a)). The user begins to modify the fuselage curves according to design requirements and later adapt the wing accordingly. The empennage is automatically sized depending on the given fuselage and wing geometry parameters.

\subsection{Geometry Model}

After the initial setup of the global geometry/dimensions of the aircraft, a more detailed geometry can be developed. The user chooses the number of frustums needed 


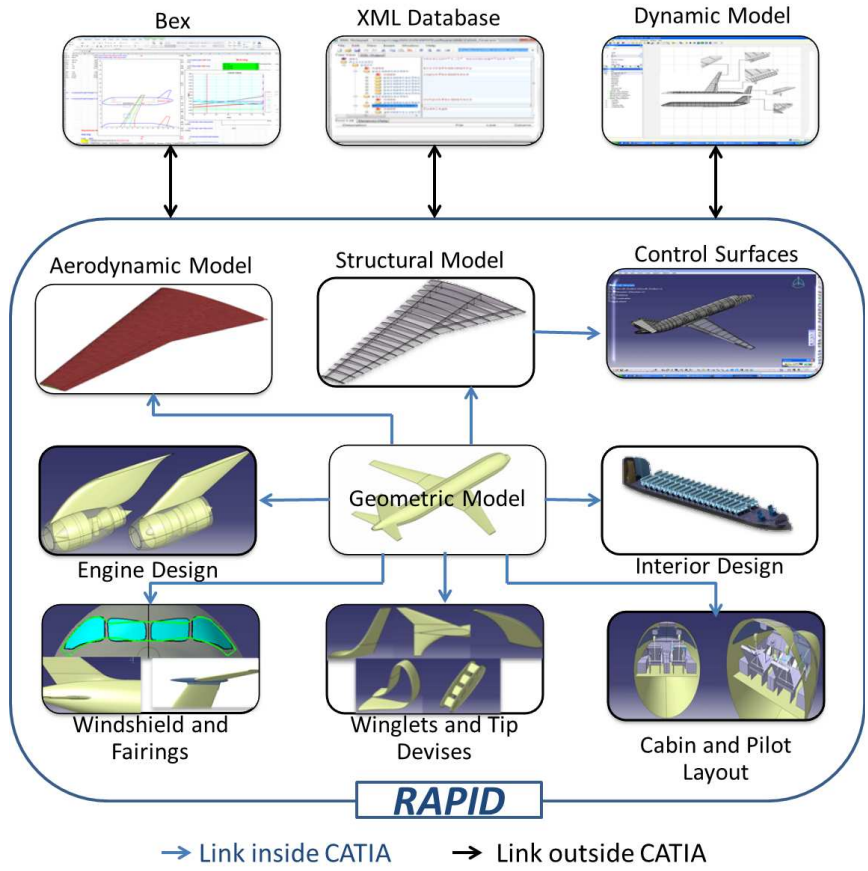

Fig. 3 RAPID Tool

for the fuselage and the number of partitions needed for wing, empennage and canard depending on the requirement. In the following Sections, the KBS geometry definitions are explained in detail.

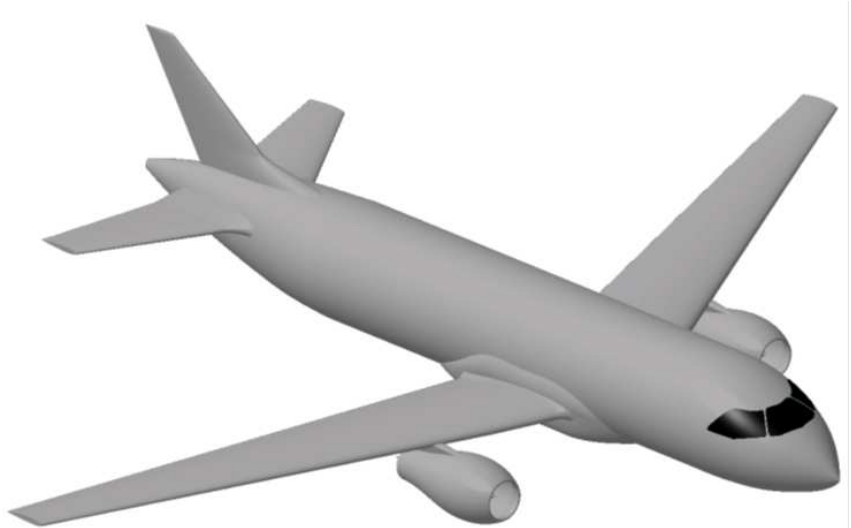

Fig. 4 Example of Civil transport aircraft geometry loaded from database

\subsubsection{Fuselage Geometry Definition}

The Fuselage wire-frame is composed of four supporting splines; namely upper curve, bottom curve, side curve and center curve (Fig. 5 (b)). The splines are created in a desired manner which are further taken as reference for the instantiation of frustums. The fuselage as described by Eq. 1 is a function of splines, fuselage length, fuselage width, fuselage height and number of frustums. Every spline contains ' $n$ ' number of points as described by Eq. 2, the least number of points that a spline can contain is limited to two points. A frustum is formed by two cross-sections joined by a surface. Bézier curves are used at the cross-section for each frustum; they are parametric and can be modified to get the desired result (Fig. 6).
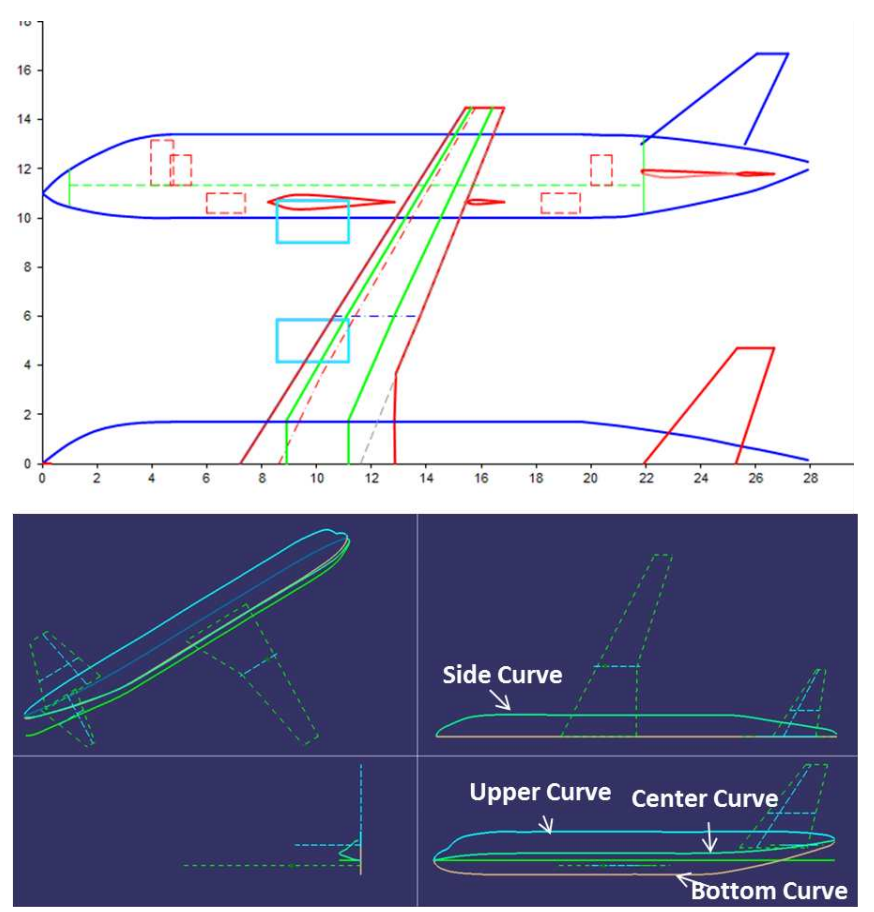

Fig. 5 (a) Fuselage curves in BeX (Top) [21]; (b) Fuselage curves in RAPID (Bottom)

\section{Establishing global fuselage geometry:}

$f u=f\left(S_{p}, L_{f}, W_{f}, H_{f}, C_{s}\right)$

$$
\begin{aligned}
& \mid S_{p}(Z)=\sum_{n=0}^{n} f_{i}(z) P_{j} \\
& \quad j=[2, n) ; P_{0}^{x}=0 ; P_{n}^{x}=L_{f} \\
& n_{x}-1<n_{x}<n_{x}+1 \\
& \triangle x=\frac{L_{f}}{n-1} \\
& \quad n \in \mathbb{N}
\end{aligned}
$$

A quarter of the fuselage cross-section segment is represented by third-order Bézier curve. The angle is 
measured with respect to the horizontal line for "upper line" and "lower line" and angle is measured with respect to the vertical line for "side upper line" and "side lower line". Point 1, 4 and 7 shown in Fig. 6 are the intersection points with the fuselage spline curves while points $2,3,5$ and 6 represent the control points of the Bézier curve; these points are positioned along the respective lines as a fraction. The fuselage cross-section is represented by Eq. 3 as a function of the points and respective angles with respect to horizontal and vertical lines (Fig. 6).

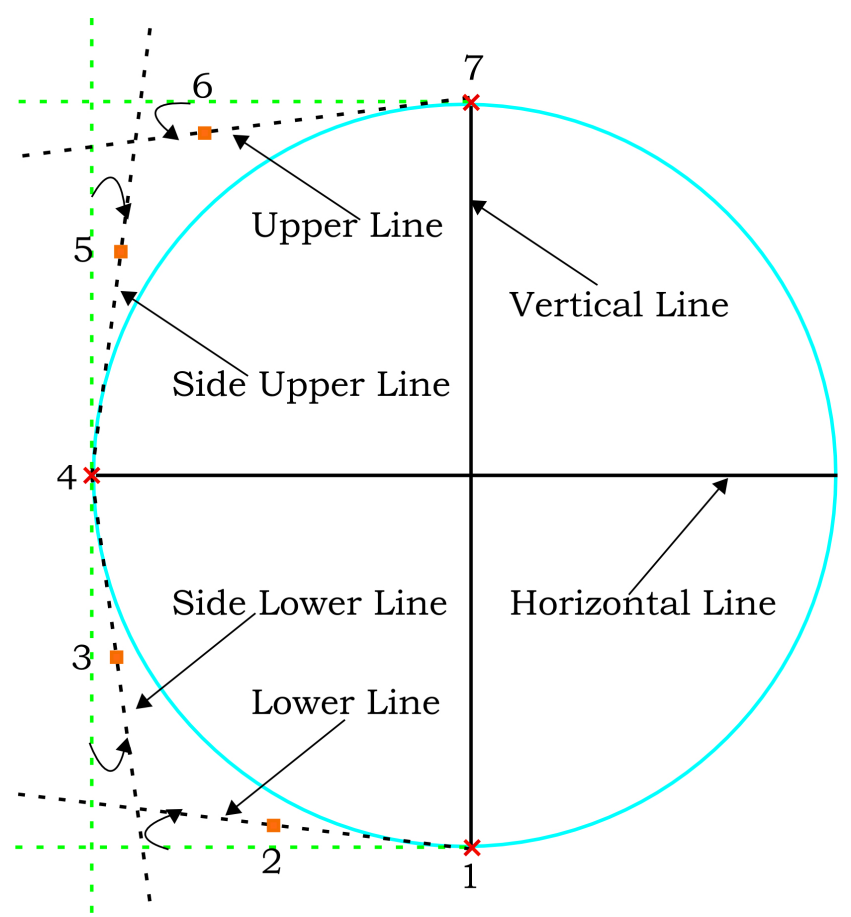

Fig. 6 Description of RAPID fuselage Cross-section [1]

\section{Establishing fuselage cross-section:}

$C_{s}^{i}:=f(p, \alpha)$

$$
\begin{aligned}
& \mid i=1,1, \ldots n \\
& n \in \mathbb{N} \\
& {\left[p_{1}^{i}, p_{4}^{i}, p_{7}^{i}\right]:=f\left(C_{u}, C_{l}, C_{c}, C_{s}^{i}\right)} \\
& {\left[p_{2}^{i}, p_{3}^{i}, p_{5}^{i}, p_{6}^{i}\right] \in[0,1]} \\
& {\left[\alpha^{i}{ }_{p_{2}}, \alpha^{i}{ }_{p_{3}}, \alpha_{p_{5}}^{i}, \alpha_{p_{6}}^{i}\right] \in\left[0, \frac{\pi}{2}\right]}
\end{aligned}
$$

\subsubsection{Wing Geometry Definition}

The wing wire-frame is generated by taking reference area, aspect ratio, taper ratio, and sweep as references, as represented by Eq. 4. The user has an option to choose the sweep angle either from leading edge or at $25 \%$ root chord to obtain trapezoidal wing area (shown in dotted line in Fig. 7). There are also other reference area methods to choose from such as Double delta, Gross Method and Wimpress Method. RAPID uses the trapezoid area as a reference, after instantiating the required number of partitions, the chord at each airfoil can be modified to obtain different wing shapes as shown in Fig. 7.

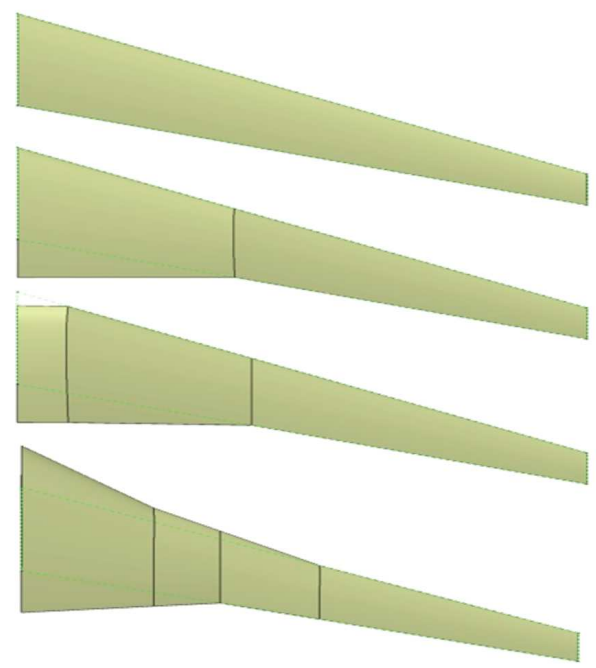

Fig. 7 Different wing shapes modified after instantiation of partitions

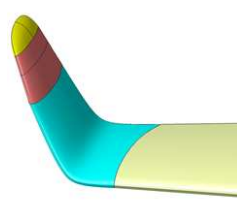

Blended

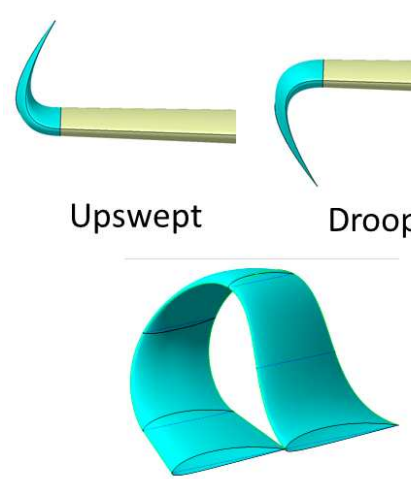

Spiroid

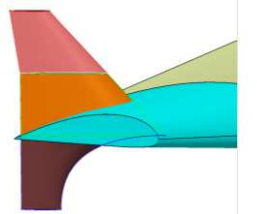

Wing Fence

Raked
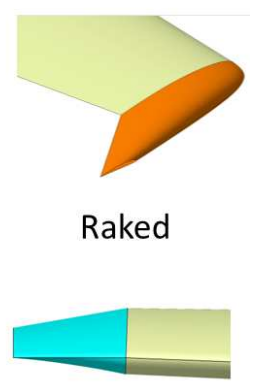

Hoerner
Fig. 8 Different types of Winglets [22] 
Establishing wing geometry:

$$
\begin{aligned}
& w=f\left(S, A_{R}, \lambda_{i}, \wedge_{i}, k_{j}, w_{p}\right) \\
& \mid i=1,2, \ldots n \\
& j=0,1,2 \ldots n-1 \\
& n \in \mathbb{N}
\end{aligned}
$$

Each partition is made up of two airfoils joined by a surface. The airfoils are generated using third-order Bézier curves, Eq. 5 describes each partition and Eq. 6 presents the Bézier equation for each airfoil of the partition. The same partition template is used for horizontal tail, vertical tail and canard. Since the airfoil is parametrically defined, it can be used to obtain "N" number of airfoil shapes [23]. Different types of winglets and wing tip devices can be chosen (Fig. 8). The wing wireframe is first instantiated and later the number of wing partitions are instantiated. The projected areas of each partition are summed up to give the final area of wing and winglets.

\section{Establishing wing partition:}

$$
\begin{aligned}
& w_{p}^{i}:=f(B(t), \Gamma, \phi, \theta) \\
& \mid i=1,2, \ldots n \\
& n \in \mathbb{N} \\
& B(t)=(1-t)^{3} P_{0}+3(1-t)^{2} t P_{1}+3(1-t) t^{2} P_{2}+t^{3} P_{3} \\
& t \in[0,1] \\
& {\left[\Gamma^{i}, \phi^{i}, \theta^{i}\right] \in\left[-\frac{\pi}{2}, \frac{\pi}{2}\right]}
\end{aligned}
$$

\subsubsection{Engine Design}

Two types of engines (Fig. 9), turbofan and turbojet can be designed in RAPID. Thrust, Specific fuel consumption (SFC), Weight, Length, Diameter and Bypass ratio are the key parameters that size the engine. Turbofan engine is designed to suit commercial aircraft engine dimensions with a bypass ratio ranging from 3 to 20 ; turbojet engine is designed to suit the dimensions of military and business jet engines without after burner and a bypass ratio ranging from 0.1 to 15 .

Nacelle geometry design depends on the type of engine and various parameters that can be changed to obtain the desired contour. Mixed-flow and separate-jet are two kinds of nacelles available; straight and smooth pylon types can be chosen consequently. The pylon is designed in contest with nacelle, start and end values are changed accordingly. Air inlet and duct for military application is currently a work in progress.

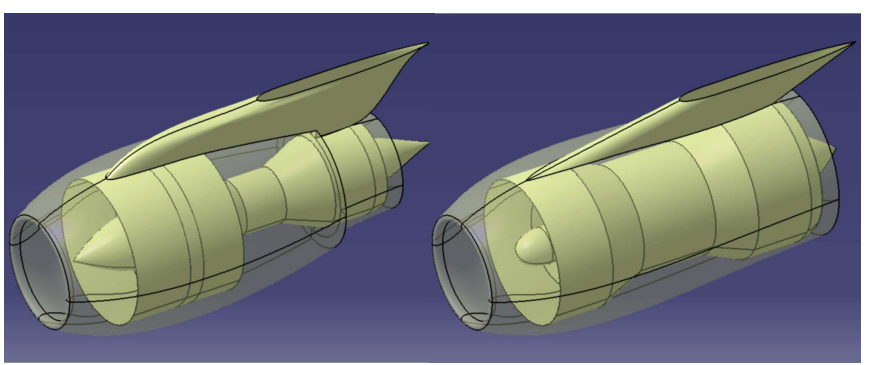

Fig. 9 Turbofan (left) and turbojet engine (right) [1]

\subsection{Interior Design}

Comfort is the privilege that a passenger craves for while traveling. Aircraft interiors is a major part of the aircraft design process: Cabin space has to be utilized in an intelligent fashion using most of the space, while maintaining the comfort factors for passenger and a accommodating maximum number of passengers according to the requirement.

\subsubsection{Cockpit Design}
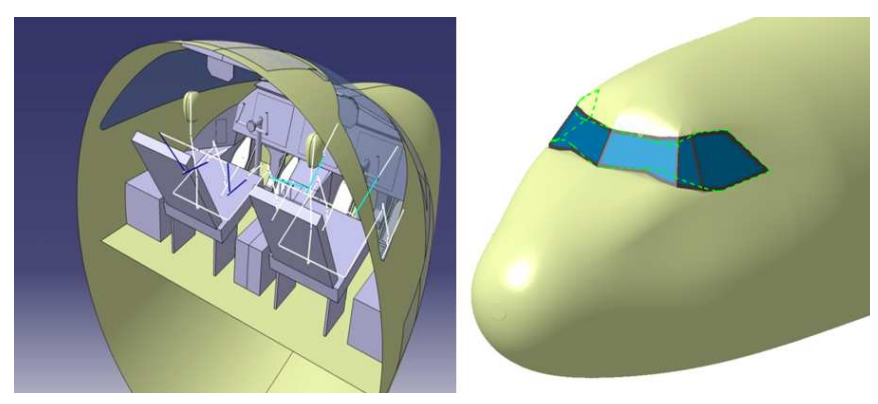

Fig. 10 Cockpit and Windshield model [20][24]

The cockpit design consists of windshield design, cockpit layout and ergonomic study. Flat panels and blended windshield can be generated. The windshield uses visibility pattern as the wire-frame and a different number of panels can be instantiated as shown in Fig. 10.

\subsubsection{Cabin Layout}

Seating layout, doors, windows, galley, lavatory and containers can be configured on the basis of cabin interior layout. FAR 25 rules have been applied to all the entities listed above. The overall length of the cabin needed is computed and the user will know the cabin length available at all times. Depending on the number of passengers, number and type of galleys, number of trolleys in each galley and number of food trays in each 
trolley needed are computed. The whole weight of the cabin is computed after instantiation.

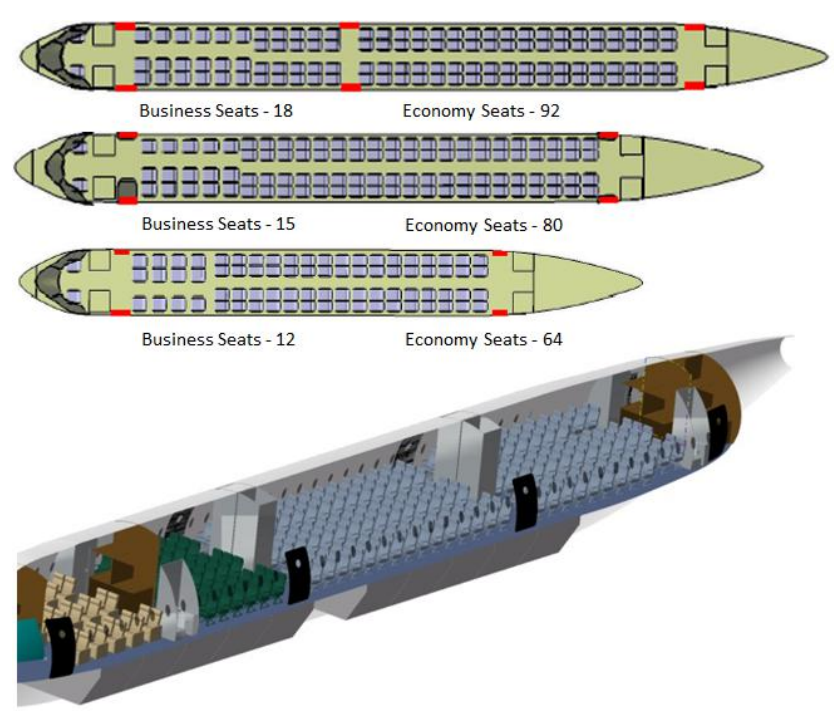

Fig. 11 Cabin Layout Interface and Cabin Interior

\section{Design Space}

Information is congregated in the product from the conceptual design to detail design. Table 2 shows the number of parameters used to create the model in Fig. 12 and Fig. 13. These aircrafts present singular design points in the design space obtained from the initial requirements. To investigate the robustness and flexibility of the geometry design space, three tests were conducted on the kinked wing of a civil aircraft shown in Fig. 12.

Table 1 Number of parameters for aircraft's in Fig. 12 and Fig. 13

\begin{tabular}{|c|c|c|c|c|}
\hline $\begin{array}{c}\text { CAD } \\
\text { Parts }\end{array}$ & $\begin{array}{c}\text { Number of } \\
\text { parameters } \\
\text { for } \\
\text { Wireframe }\end{array}$ & $\begin{array}{c}\text { Number of } \\
\text { parameters } \\
\text { for Surfaces }\end{array}$ & $\begin{array}{c}\text { Total } \\
\text { number of } \\
\text { Parametrs } \\
\text { for Civil } \\
\text { Aircraft }\end{array}$ & $\begin{array}{c}\text { Total } \\
\text { number of } \\
\text { Parameters } \\
\text { for Military } \\
\text { aircraft }\end{array}$ \\
\hline Fuselage & 93 & 108 & 201 & 201 \\
\hline Wing & 19 & 71 & 90 & 90 \\
\hline Horizontal Tail & 18 & 46 & 64 & 64 \\
\hline Vertical Tail & 18 & 46 & 64 & 64 \\
\hline Canard & 18 & 46 & - & 64 \\
\hline Engine Civil & 11 & 34 & 45 & - \\
\hline Engine Military & 11 & 50 & - & 66 \\
\hline \multicolumn{2}{|c|}{ Total number of parameters } & 464 & 549 \\
\hline
\end{tabular}

modeFRONTIER ${ }^{\circledR}[25]$ was used to compute different designs. The design of experiments was created using Latin Hypercube sampling to obtain uniformly distributed values for each input parameter as shown in Table 2. Robustness and flexibility of the designs are computed [26] as shown in Table 3. The design space value in Table 3 is affected by the number and range of the design parameters involved in the process; it would become very large once all the parameters in Table 1 are used to compute the design space.

Table 2 Wing test case setup

\begin{tabular}{|c|c|c|c|c|c|c|c|}
\hline \multirow[b]{2}{*}{ Design Parameter } & \multirow[b]{2}{*}{ Reference } & \multicolumn{2}{|c|}{ Wing Test 1} & \multicolumn{2}{|c|}{ Wing Test 2} & \multicolumn{2}{|c|}{ Wing Test 3} \\
\hline & & Minimum & Maximum & Minimum & Maximum & Minimum & Maximum \\
\hline AR & 9.71 & \begin{tabular}{|l|}
4.71 \\
\end{tabular} & 14.71 & 0.7147 & 18.71 & \begin{tabular}{|l|}
0.7147 \\
\end{tabular} & 18.71 \\
\hline TROuterWing & 0.14 & 0.09 & 0.19 & 0.04 & 0.24 & 0.04 & 0.24 \\
\hline TRInnerWing & 0.53 & 0.13 & 0.93 & 0.03 & 1.03 & 0.03 & 1.03 \\
\hline kingPosition $(\mathrm{mm})$ & $\begin{array}{c}6407 \\
(0.3812)\end{array}$ & 5907 & 6907 & 5407 & 7407 & 0.3212 & 0.4407 \\
\hline wingArea (m2) & 116.32 & 66.32 & 166.32 & 16.32 & 216.32 & 16.32 & 216.32 \\
\hline $\begin{array}{c}\text { sweeplnnerWing } \\
\text { (deg) }\end{array}$ & 21.43 & -28.57 & 71.43 & -43.57 & 86.43 & -43.57 & 86.43 \\
\hline $\begin{array}{l}\text { sweepOuterWing } \\
\text { (deg) }\end{array}$ & 21.43 & -28.57 & 71.43 & -43.57 & 86.43 & -43.57 & 86.43 \\
\hline
\end{tabular}

"Wing Test 1" has a lesser design space compared to the rest of the test cases in Table 2. All "Wing Test 1" designs have been successful even though the kinkPosition parameter is defined directly as a length. In "Wing Test 2" about $25 \%$ of the designs have failed because the kink position is placed outside the wing for minimum values of aspect ratio (AR) and wingArea. Robustness in "Wing Test 2" is therefore affected by the poor parametrization of the kink position. To improve robustness, the kink position parametrization was given as a ratio of the span of the wing in the "Wing Test 3" with an identical design space as that of "Wing Test 2". It can be seen from Table 3 for "Wing Test 3" that flexibility and robustness of the model increased significantly: only 31 of 2000 designs failed in this case. It has been observed that the failure of these designs occurred for values of "sweepInnerWing" and "sweepInnerWing", at angles close to 85 degrees and above, thus close to the boundary of the design space. The robustness of the model increases considerably by having the kink position parameterized as a ratio of the span.

Table 3 Robustness and flexibility for results of wing design space tests

\begin{tabular}{|l|c|c|c|c|c|}
\hline & $\begin{array}{c}\text { Number of } \\
\text { Designs }\end{array}$ & $\begin{array}{c}\text { Number of } \\
\text { Parameters }\end{array}$ & $\begin{array}{c}\text { Design } \\
\text { Space }\end{array}$ & Robustness & Flexibility \\
\hline Wing Test 1 & 1000 & 7 & 13.59 & 1 & 13.59 \\
\hline Wing Test 2 & 2000 & 7 & 19.33 & 0.751 & 14.52 \\
\hline Wing Test 3 & 2000 & 7 & 19.33 & 0.985 & 19.04 \\
\hline
\end{tabular}

The normalized sensitivity matrix of the kinked wing is shown in Table 4, wingArea and AR are the two parameters that mainly affect the system characteristics 
of the wing. It is observed that, by effective parametrization, a high degree of Robustness and Flexibility is obtained.

Table 4 Normalized Sensitivity Matrix of the wing

\begin{tabular}{|c|c|c|c|c|c|}
\hline & \multicolumn{5}{|c|}{ Design Parameters } \\
\hline System Charactersics & AR & TROuterWing & TRInnerWing & kinkPosition & wingArea \\
\hline middleChord & -0.24 & -0.10 & 0.00 & -0.37 & 0.61 \\
\hline rootChord & -0.24 & -0.10 & -1.01 & -0.38 & 0.61 \\
\hline tipChord & -0.50 & 0.88 & 0.00 & 0.00 & 0.50 \\
\hline wingSpan & 0.50 & 0.00 & 0.00 & 0.00 & 0.50 \\
\hline
\end{tabular}

\subsection{Data translation RAPID/Tango implementation}

This section presents the application examples of the framework, showing the data build up and its translation between RAPID and Tango and vice versa. Two examples have been tested to investigate the data flow processed in the correct approach. A number of parameters are accessible for the user in order to obtain various configurations. This might lead to a geometry that is over-defined.

\subsubsection{Civil Aircraft}

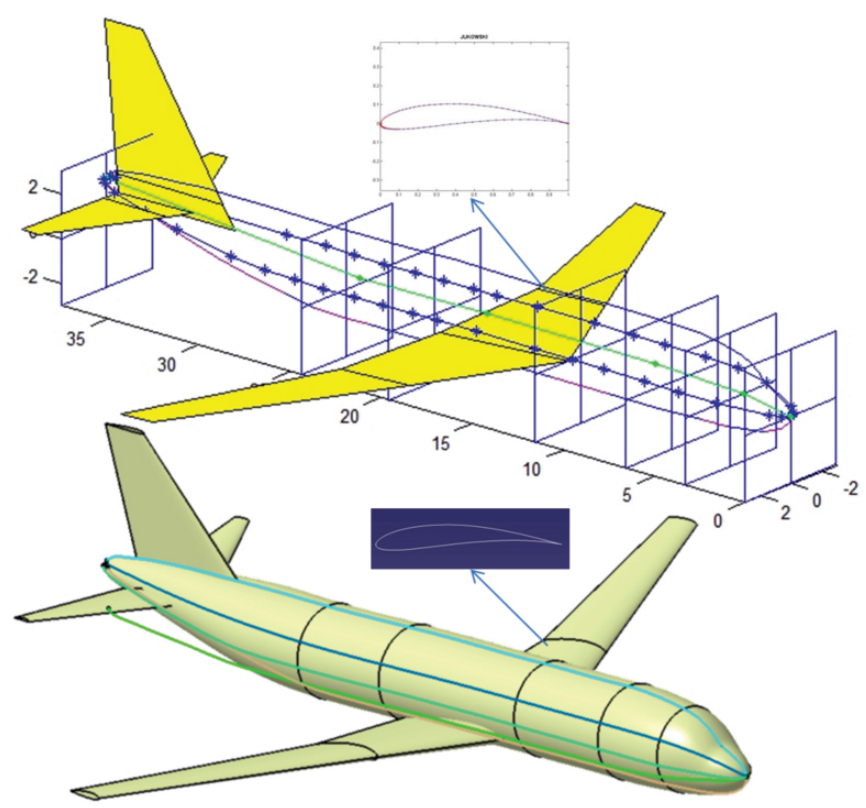

Fig. 12 Civil Aircraft in Tango (top) and in RAPID (bottom)

In this application the double delta reference method is used for a civil transport aircraft design as shown in Fig. 12. The cross-sections of the fuselage range from a circle to an ellipse. The data were successfully exchanged in both directions.

\subsubsection{Military Aircraft}

A more complex model (fighter aircraft) was selected to examine the framework as shown in Fig. 13. It is to notice that the data structure of both examples is similar, with only modified parameters and the addition of a lifting surface (canard) in the fighter example.

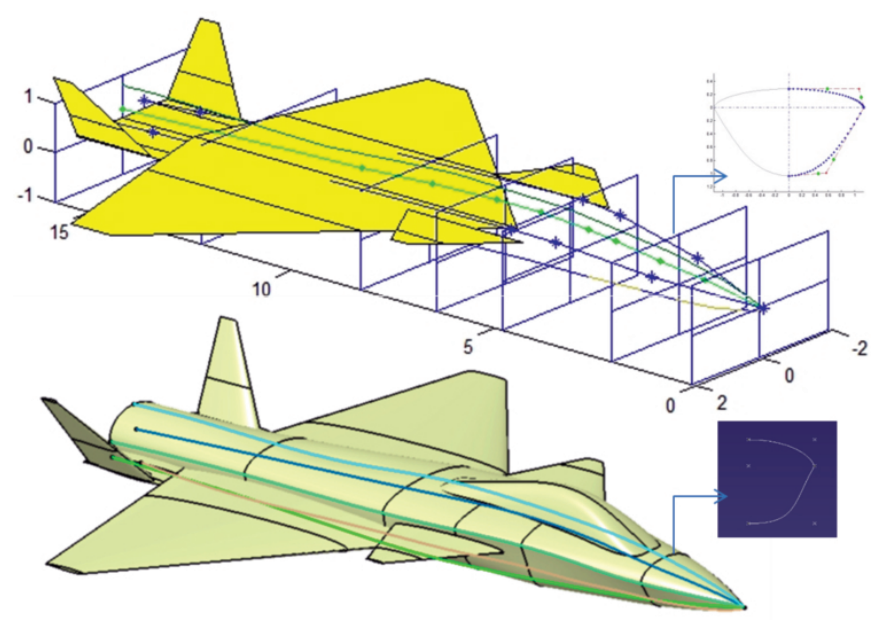

Fig. 13 Military Aircraft in Tango (top) and in RAPID (bottom)

\section{Data Management}

The flow of data between each discipline in a multidisciplinary design environment (Fig. 14) is coupled and saved in XML format [27] [28]. The database definition (including several component libraries like functional assemblies) is parametrically defined in such a manner that a data refinement over time alongside the project is possible.

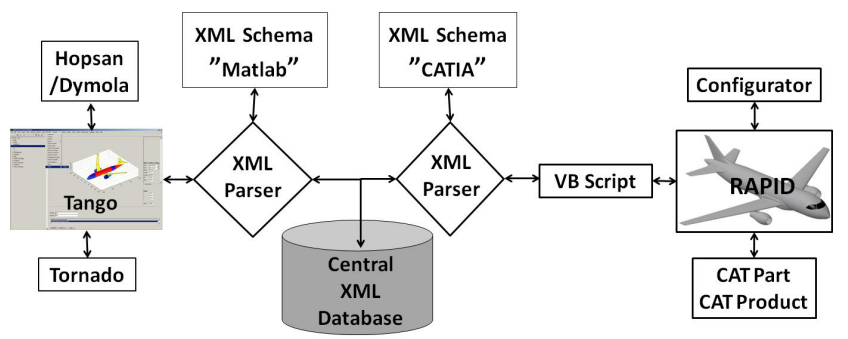

Fig. 14 XML data flow between applications RAPID and Tango with the help of XSLT.

XML is made up of markup tags and data to represent the information. An XML forms a tree structure; this makes it easy to retrieve data and find relationship between different information. Transformation of 
XML documents is performed using XSL Transformations (XLST). XSLT uses XPath language to navigate in XML documents. It can serve for complex translations such as element and attribute editing (add, remove, replace), rearrangement, sorting, perform tests and make decisions [29].

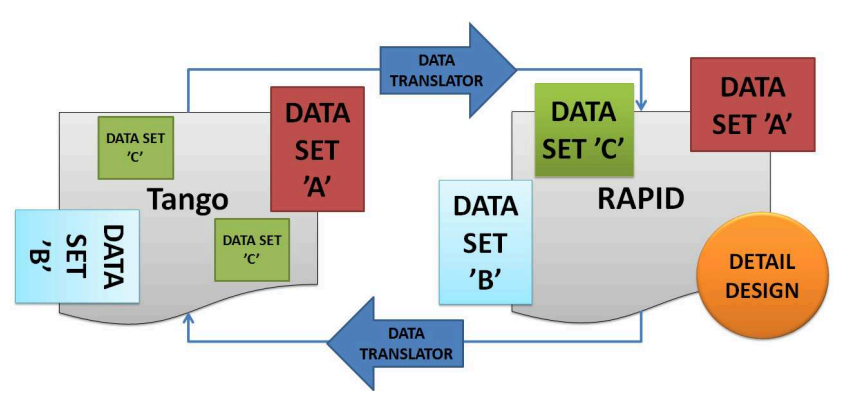

Fig. 15 Data communication with different subsets of geometry.

The functional approach is different in RAPID and Tango as the fundamental design approach varies in CAD and technical computing/programming language. Data is translated between the programs using the data translator. In Fig. 15 dataset 'A' of the initial geometry representation is available in both programs. Later, dataset ' $\mathrm{B}$ ' is added in Tango and is updated in RAPID, e.g., a canard is added to the existing configuration. It is to note that dataset ' $\mathrm{C}$ ' created in RAPID is split into two subsets in Tango; for example:- wing and the engine housing are in the same geometrical product in RAPID but this is split up into a geometrical and functional subset in Tango. This results in different local product/XML tree structures in the RAPID resp. Tango tool as shown in Fig. 16. Detail design or design addons to the geometry are not updated in Tango.

\subsection{RAPID XML Export/Import}

Excel Visual Basic for Applications (VBA) is used to configure the CATIA parameters or geometrical sets and extract information from RAPID and generate into an XML. Configuring the parameters through Excel will reduce the effort of updating the code whenever a new parameter/geometrical set is need to be added to the XML. Strings from CATIA and Excel are parsed and matching entities are added to the XML tree.

For efficient XML editing, Microsoft XMLDOM object is used in the VBA section to translate the parameter/geometric sets into XML. The DOM (Document Object Model) object creates the XML file and takes care of the structure and formatting. This dataset tree related access method also supports XML modification without any hassles or cumbersome coding.

To import the values to RAPID, the XML file is loaded into a DOM. This DOM is recursively parsed for the required information and tags, needed by the RAPID geometry model.

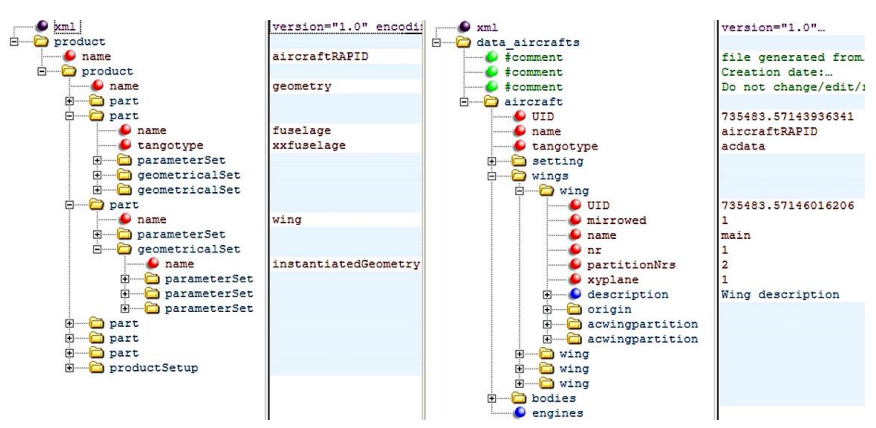

Fig. 16 Data Structure adapted towards the tools needs (Right side: Tango XML, Left Side: RAPID XML)

\subsection{Tango XML}

Tango makes usage of the underlying Java DOM application classes in Matlab that serves for the XML data handling. This data is handled object oriented within geometrical or functional classes, so that every class includes the class-related XML parsing functionalities. This method allows for greater flexibility and fast replacement or appending of new classes.

The basic classes are product-geometry related (e.g., wing and underlying wing partition class) whereas the higher level classes are product-functional related (e.g., fuel system, primary flight control system). This class reference transition within the dataset makes it necessary to work with part pointers in order to link the functional classes with its related geometrical entities and properties in the geometry related classes; Examples are the control surfaces (geo. def.) that are part of the primary flight control system (sys. def.) and the wing fuel tanks (geo. def.) that are part of the fuel/propulsion system (sys. def.). By these links, the strict hierarchal XML (tree) data structure becomes extended by crossbranch couplings, specified by the part pointers.

\section{Academic Implementation}

To test RAPID and get user feedback, the framework has been applied as a "real world test" within undergraduate student courses and aeronautical master courses at Linköping University. Two examples of this application are presented. 


\subsection{The Mid-Jet aircraft Project}

The Mid-Jet project (Fig. 17) was to build an aerobatic, aesthetic, striking and overwhelming single seat sports jet. To test and demonstrate the flight performance and characteristics a scaled model had to be built, too. As a first part of the project, a study of existing single seat sports jets was conducted and different concepts were proposed. These ideas were studied from each student team and finally the best concept was chosen for further studies.

This concept was then developed in RAPID up to the conceptual design stage for the full-scale version of the Mid-Jet. From this, a subscale version intended for prototype realization was developed up to the detailed design stage by adding different features to the RAPID model successively. With this model, a demonstrator on a scale of 1:2.8 was built and successfully flight tested. It is to note that the period between the first design studies until the maiden flight of the demonstrator had only been ca. six months. Particular attention was paid to detect the usability of the conceptual/preliminary design model within the detailed design stage.

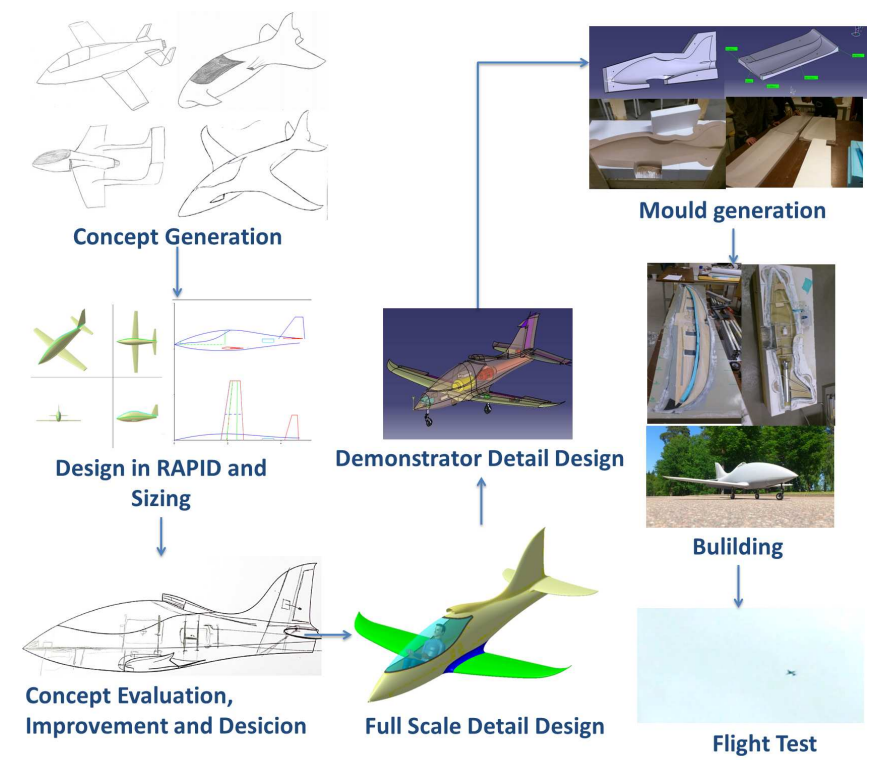

Fig. 17 Mid-Jet aircraft project process

\subsection{Very Light Jets (VLJs)}

The VLJs project was to design a two-seater and a fourseater aircraft. Both the aircrafts were to be designed around the DGEN-380 engine. The aircrafts should be flown by normal, average skilled pilots e.g., flying club members. Cruise flight altitude is below $20000 \mathrm{ft}$ with

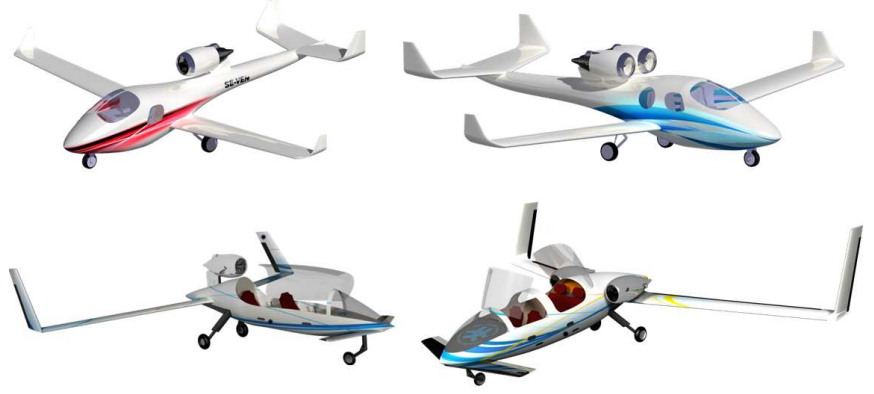

Fig. 18 Artistic view of students Very Light Jets; Single engine 2-seater (Left), Twin engine 4-seater (Right).

unpressurized cabins. Main design solutions were presented including seating arrangement, structural layout, entrance door placements and design, engine placement, fuel tank integration, baggage and landing gear design. Weight and general performance of the aircraft were evaluated along with center of gravity range, stability and trimmability. The artistic view of the aircraft designed in RAPID by the students is shown in Fig. 18.

\section{Conclusion}

This paper shows that it is possible to communicate between the analytical tool (Tango) and the 3D environment (RAPID). The knowledge-based automated design of RAPID is presented along with its applications. As a result, different types of aircraft configurations can be obtained with less effort. As RAPID is based on relational design, any changes made to the geometric model will update the entire design. The designer can achieve different cross-sections for fuselage and airfoils for lifting surfaces. An initial size of the engine is obtained from the engine design; nacelle and pylon can be shaped accordingly. The geometry model is carefully defined to carry over to the preliminary design, while obtaining a robust, wide design space as shown in Sect. 4. Details such as cockpit model, windshield, fairings, winglets and cabin interior layout can be observed at early stages of design. An XML database is used to save the design data and also communicate with the other framework tools.

\section{Future Work}

Future work includes weight estimation, drag calculations, structural design and optimization framework. Improvements in the existing structural model and aerodynamic model are needed to enable automatic mesh update in the optimization framework. Systems inte- 
gration in CAD model is needed to estimate the volume available for best fit of the components.

\section{Acknowledgements}

This research is supported by the Swedish National Aviation Engineering Program (NFFP) jointly operated by the Swedish Armed Forces, Swedish Defense Material Administration (FMV) and the Swedish Governmental Agency for Innovation Systems (VINNOVA)[30]. The authors thank the NFFP founders for this support.

The authors would also like to thank the students of Aircraft Conceptual Design and Aircraft Project courses at Linköping University for their excellent work during the courses as well the Mid-Jet project course team leader and test pilot David Lundström for his great efforts.

\section{References}

1. Staack, I., Raghu Chaitanya, M., and Krus, P., "Parametric Aircraft Conceptual Design Space," 28th Congress of the International Council of the Aeronautical Science, Brisbane, Australia, 2012.

2. Raymer, D., RDS-student: software for aircraft design, sizing, and performance, Vol. 10, AIAA education series, Washington DC, 2006.

3. Hahn, A., "Vehicle Sketch Pad: A Parametric Geometry Modeler for Conceptual Aircraft Design," Proc. 48th AIAA Aerospace Sciences Meeting, American Institute of Aeronautics and Astronautics, Orlando, Florida, Jan 2010.

4. Ziemer, S., Glas, M., and Stenz, G., "A Conceptual Design Tool for multi-disciplinary aircraft design," IEEE Aerospace Conference, Vol. 0, 2011, pp. 1-13.

5. j2 Universal Framework, "[Online; Accessed 19-May2015]", http://www.j2aircraft.com/.

6. ADS, "Aircraft Design Software," "[Online; Accessed 19May-2015]", http://www.pca2000.com.

7. Piano, "Aircraft design and Competitor Analysis," "[Online; Accessed 19-May-2015]", http://www.piano.aero/.

8. RAGE, "Rapid Aerospace Geometry Engine, Desktop Aeronautics," "[Online; Accessed 19-May-2015]", http://www.desktop.aero/products/rage.

9. CEASIOM, "Computerized Environment for Aircraft Synthesis and Integrated Optimization Methods software," "[Online; Accessed 19-May-2015]", http://www.ceasiom.com.

10. "PADLab Software," "[Online; Accessed 19-May-2015]", http://www.luftbau.tuberlin.de/menue/forschung/padlab.

11. Munjulury, R. C., Knowledge Based Integrated Multidisciplinary Aircraft Conceptual Design, Licentiate thesis no. 1661, Department of Management and Engineering, Linköping University, Linköping, Sweden, 2014.

12. "CATIA V5 Release21," "[Online; Accessed 19-May2015]", http://www.3ds.com/.

13. Melin, T., "A vortex lattice MATLAB implementation for linear aerodynamic wing applications," Master's Thesis, Department of Aeronautics, Royal Institute of Technology (KTH), Stockholm, Sweden, 2000.
14. Munjulury, R. C., Staack, I., Abdalla, A., Melin, T., Jouannet, C., and Krus, P., "Knowledge-based Design for Future Combat Aircraft Concepts," Proc. 29th Congress of the International Council of the Aeronautical Science, St. Petersburg, Russia, 2014.

15. Rosenfeld, L., "Handbook of Solid Modeling," chap. Solid Modeling and Knowledge-based Engineering, McGrawHill Inc., New York, USA, 1995, pp. 91-911.

16. Cooper, S., Fan, I., and Li, G., Achieving competitive advantage through knowledge-based engineering: a best practice guide, Department of Trade and Industry (DTI), UK, Jun 1999.

17. La Rocca, G. and Van Tooren, M., "Enabling distributed multi-disciplinary design of complex products: a knowledge based engineering approach," Journal of Design Research, Vol. 5, No. 3, Aug 2007, pp. 333-352.

18. Amadori, K., Geometry Based Design Automation: Applied to Aircraft Modeling and Optimization, Ph.d thesis no. 1418, Department of Management and Engineering, Linköping University, Linköping, 2012.

19. Tarkian, M., Design Automation for Multidisciplinary Optimization, Ph.d thesis no. 1479, Department of Management and Engineering, Linköping University, Linköping, 2012.

20. Singh, A. N., Raghu Chaitanya, M., Govindarajan, V. K., and Krus, P., "Knowledge Based Design Methodology for Generic Aircraft Windshield and Fairing-A Conceptual Approach," 51st AIAA Aerospace Sciences Meeting including the New Horizons Forum and Aerospace, American Institute of Aeronautics and Astronautics, Grapevine, Texas, USA, Jan 2013.

21. Berry, P. and Jouannet, C., "Recycling Old Weight Assessment Methods and Giving them New Life in Aircraft Conceptual Design," 28th Congress of the International Council of the Aeronautical Science, Brisbane, Australia, 2012.

22. Rajendran, S., Design of Parametric Winglets and Wing tip devices : A Conceptual Design Approach, Master's thesis, Department of Management and Engineering,Linköping University, Linköping, 2012.

23. Melin, T., Parametric Airfoil Catalog, Linköping University, 1st ed., 2013.

24. Tassel, W., Development of a Complete Parametric CAD Model of a Cockpit Layout for Civil Airplane Under CATIA CAD Software, Master's thesis, Department of Management and Engineering,Linköping University, Linköping, 2012.

25. "modeFrontier 4.5.2," "[Online; Accessed 19-May-2015]", http://www.esteco.com/modefrontier.

26. Amadori, K., Tarkian, M., Ölvander, J., and Krus, P., "Flexible and Robust CAD Models for Design Automation," Advanced Engineering Informatics, Vol. 26, No. 2, Apr 2012, pp. 180-195.

27. Lin, R. and Abdollah, A., "An XML-Based Integrated Database Model for Multidisciplinary Aircraft Design," Journal of Aerospace Computing, Information, and Communication, Vol. 1, No. 3, Mar 2004, pp. 154-172.

28. Lee, H.-J., Lee, J.-W., and Lee, J.-O., "Development of Web services-based Multidisciplinary Design Optimization framework," Advances in Engineering Software, Vol. 40, No. 3, Mar 2009, pp. 176-183.

29. "XML and DOM Objects," "[Online; Accessed 19-May2015]", http://www.w3.org/.

30. VINNOVA, "Swedish national aviation engineering research programme," http://www.vinnova.se/en/Ouractivities/Cooperation-Programmes/National-AviationEngineering-Research-Programme/. 